\title{
EXPERIMENTAL INVESTIGATION ON DYNAMIC BEHAVIOUR OF HEAVY-HAUL RAILWAY TRACK INDUCED BY HEAVY AXLE LOAD
}

\author{
Zhiyong $\mathrm{SHI}^{1}$, Kaiyun $\mathrm{WANG}^{2 *}$, Dawei $\mathrm{ZHANG}^{3}$, Zaigang $\mathrm{CHEN}^{4}$, \\ Guanghao $\mathrm{ZHAI}^{5}$, Daoxing HUANG ${ }^{6}$ \\ ${ }^{1-4}$ State Key Laboratory of Traction Power, Southwest Jiaotong University, China \\ ${ }^{5,}{ }^{6}$ Mao Yisheng Honors College, Southwest Jiaotong University, China
}

Received 3 May 2016; revised 30 July 2016; accepted 17 August 2016

\begin{abstract}
The damage to the track structure and the influence to the line deformation have greatly deteriorated with the increase of the axle load compared with that of the ordinary trains. However, there is a paucity of experimental research on the dynamic influence of the heavier haul freight trains on the railway tracks. The objective of this study is to investigate the dynamic behaviour of heavy-haul railway track induced by heavy axle load by field experimental tests. The wheel-rail dynamic force, the track structure dynamic deformation and the track vibration behaviour are measured and analysed when the train operates in the speed range from 10 to $75 \mathrm{~km} / \mathrm{h}$ and the axle load of vehicles varies from 21 to $30 \mathrm{t}$. Comparisons between the results for the axle conditions of 25 and $30 \mathrm{t}$ are made in this paper to reveal the axle load effects. It is demonstrated that part of the indicators reflecting the dynamic behaviour of the railway track increases approximately linearly with the train running speed and axle load, while others are influenced negligibly.
\end{abstract}

Keywords: heavy-haul railway, railway track, dynamic behaviour, train speed, axle load, field experiment.

\section{Introduction}

Heavy-haul transport has been widely concerned worldwide due to its advantages such as large transport capacity, high efficiency, and low transportation costs. This transportation mode is one of the major trends for freight transportation development, where expanding train formation and increasing axle load are two basic methods. As one of the basic methods, increasing the axle load has exhibited an important role in the development of heavyhaul transport. This method has been broadly adopted by all the major countries. With the increase of the axle load, the dynamic interactions between the rails and the wheels become more serious, for this reason it is highly necessary to ensure the safety of the railway track structure systems. The serious wheel-rail dynamic interactions are much more likely to cause damages or failures to the railway structural elements during their transmission to the ground through rails, sleepers and ballast bed. Therefore, a deep understanding of the dynamic performance of the railway tracks under heavy axle-load is required.

Nowadays, a number of numerical studies have been carried out to evaluate the performance of railway track structure induced by moving load (Filippov 1961; Sheng et al. 1999; Vostroukhov, Metrikine 2003; Chupin et al. 2014). However, it is quite difficult to obtain the precise dynamic response of the track structure theoretically due to the complexity of the interactions between the vehicle system and the railway system. As one of the most important methods, field-testing is usually employed in the dynamic investigations of the railways. Experimental investigations including wheel-rail force and sleeper acceleration (Askarinejad et al. 2013), the ballast acceleration (Zhai et al. 2004), the dynamic behaviour and the settlement of ballasted tracks (Al Shaer et al. 2008) and other studies (Remennikov, Kaewunruen 2006; Coelho et al. 2011) were carried out. Aiming to study the impact of heavy axle load running on the track structure, some field experiments were performed by Transportation Technology Center, Inc. (https://aar.com) (a wholly owned subsidiary of the Association of American Railroads (AAR)) since 1988 from the perspective of railway maintenance (Zeng 1988). These experimental studies indicate that the damage to the track structure and the influence to the line deformation greatly deteriorates with the increase of the axle load compared with the ordinary trains one.

${ }^{*}$ Corresponding author. E-mail: kywang@swjtu.edu.cn 
The dynamic behaviour of the track structure induced by heavy-haul trains is determined by many complicated factors such as the train speed and the axle load. Employing numerical and experimental methods, researchers has investigated the effect of train speed, axle load and other vehicle parameters on railway track structure (Kouroussis et al. 2012; Remennikov, Kaewunruen 2008). The effect of the train speed on the dynamic response of the vehicle and track systems under the condition of one partially supported sleeper was studied by Young and Li (2003), depicting that the effect of train speed will enlarge the deformation of that sleeper unsurprisingly. Kouroussis et al. (2014) comprehensively reviewed the vehicle characteristics, focusing on different train types on vibration propagation and numerical modelling approaches, and their results suggested that train type and contact conditions influenced vibration remarkably. Recently, Colaço et al. (2016) analysed the effects of vehicle mass and spacing of wheels and bogies on ground-borne vibration and found that the unsprung mass affected the vibration level greatly while semi-sprung mass and wheel/bogie spacing had negligible effect. However, the indicators in previous articles seem to be insufficient and not precise enough. Further studies on revealing the relationship between train parameters and railway track dynamic behaviour are required.

Aiming to investigate the dynamic behaviour of the heavy-haul railway track under heavy axle load condition and to present detailed analysis on the relationship between the railway dynamic indicators and the axle load/ train speed, field experimental tests on the dynamic performance of heavy-haul freight trains in Chinese ShuoHuang railway line were carried out during the period from 28 August to 18 September 2015. The test site in the Shuo-Huang heavy-haul railway line is shown in Figure 1. With information on the dynamic effect of the ballast track in heavy-haul condition provided, a better understanding on the dynamic behaviour of the railway structure is presented and it is expected that this may provide assistance to the researchers for the validation of their numerical models of the heavy freight train system.

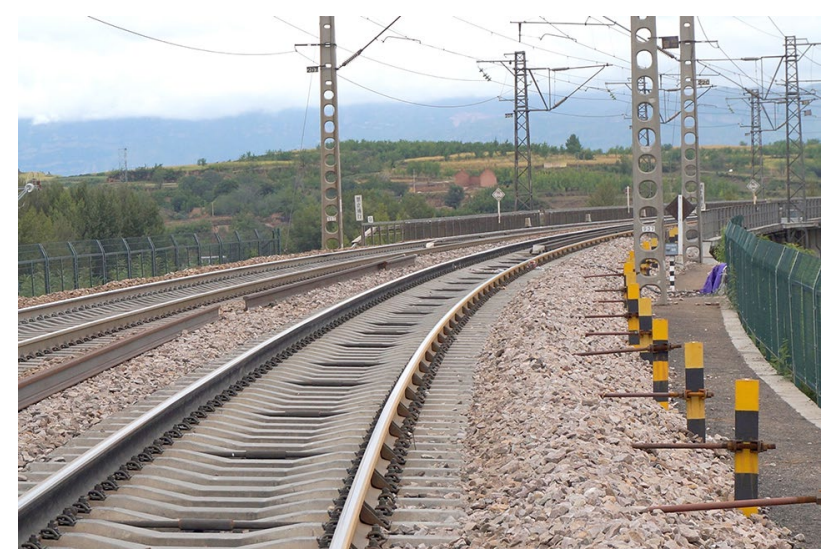

Figure 1. Test site in the Shuo-Huang heavy-haul railway line

\section{Field experimental test on dynamic performance of heavy-haul railway track}

In this field experimental test, some dynamic indicators such as the wheel-rail dynamic force, the track structure deformations, and the track structural vibrations, were measured when the heavy-haul trains operate in the speed range of $10 \ldots .75 \mathrm{~km} / \mathrm{h}$. The axle load of the vehicles in the tested heavy-haul train varies from 21 to $30 \mathrm{t}$. In this test, the measured indicators consist of wheel-rail lateral/vertical forces, rail lateral/vertical displacements, sleeper vertical displacement, rail vertical acceleration, sleeper vertical acceleration, and ballast bed vertical acceleration.

\subsection{Test conditions}

In order to acquire the railway dynamic evaluation data, the data detection system was instrumented by data acquisition devices with multi channels, accelerometers, displacement sensors, strain gauges and sensor cables. A view of the test setup is presented in Figure 2.

The field experimental tests were performed in the position of K70 + 939 (kilometre mark) in the upline of the Shuo-Huang heavy-haul railway. A curve section of ShuoHuang railway line was selected for the tests. The main parameters of the track are listed in Table 1.

Table 1. Main parameters of the ballast track

\begin{tabular}{|l|c|c|}
\hline \multicolumn{1}{|c|}{ Parameter } & Value & Unit \\
\hline Curve radius & 600 & $\mathrm{~m}$ \\
\hline Length of transition curve & 140 & $\mathrm{~m}$ \\
\hline Curve superelevation & 75 & $\mathrm{~mm}$ \\
\hline Gauge & 1.435 & $\mathrm{~m}$ \\
\hline Rail mass & 75 & $\mathrm{~kg} / \mathrm{m}$ \\
\hline Sleeper spacing & 600 & $\mathrm{~mm}$ \\
\hline
\end{tabular}

The ballast follows the Class A level in Chinese railway standards as regards the particle size, graduation and other properties of the ballast material at the test site. The embankment foundation was constructed according to Chinese railway standards. The track substructure was fairly uniform along the length of the test site.

Two specialized types of heavy-haul testing trains, namely 5400 and $23000 \mathrm{t}$ formation trains, were adopted in the test. The $5400 \mathrm{t}$ train was formed by a locomotive, a passenger vehicle for working and three kinds of vehicles, which are KM98, KM98AH and under filling KM98 (28 t axle load). The $23000 \mathrm{t}$ train was formed by a locomotive, a passenger vehicle for working, $100 \mathrm{KM} 98 \mathrm{AH}$ freight vehicles, a locomotive and 90 KM98 freight vehicles. The characteristic lengths of the KM98 vehicle and the two different formations of the test trains are shown in Figure 3.

Most of the axle load of the freight vehicles in the test train introduced above is $30 \mathrm{t}$ unless otherwise specified. In addition to these special test trains, other typical vehicles passing by were also adopted, such as $\mathrm{C} 64 \mathrm{~K}(21 \mathrm{t}$ axle load), C70 (23 $\mathrm{t}$ axle load) and C80 (25 $\mathrm{t}$ axle load). 

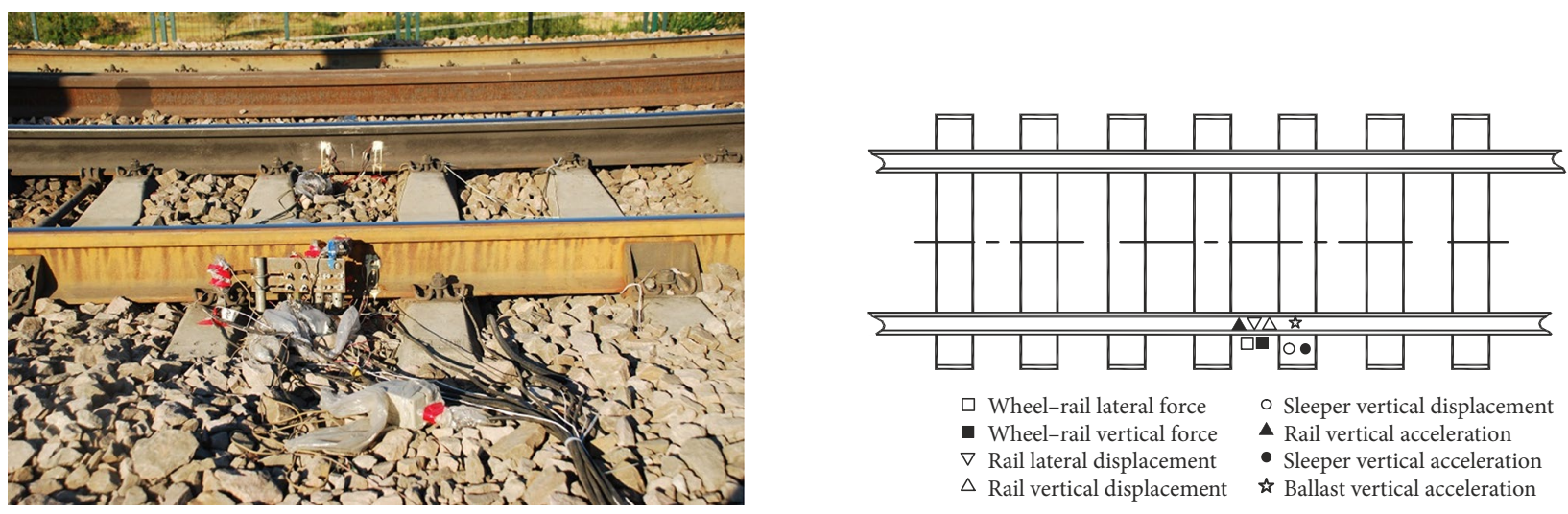

Figure 2. Field test setup

a)

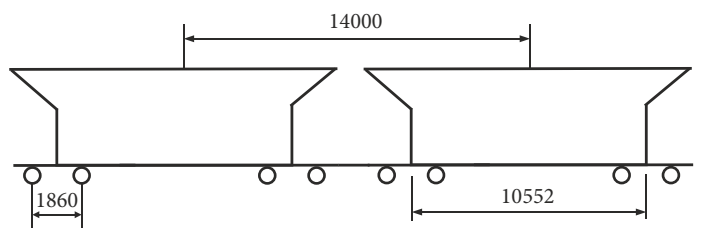

b)
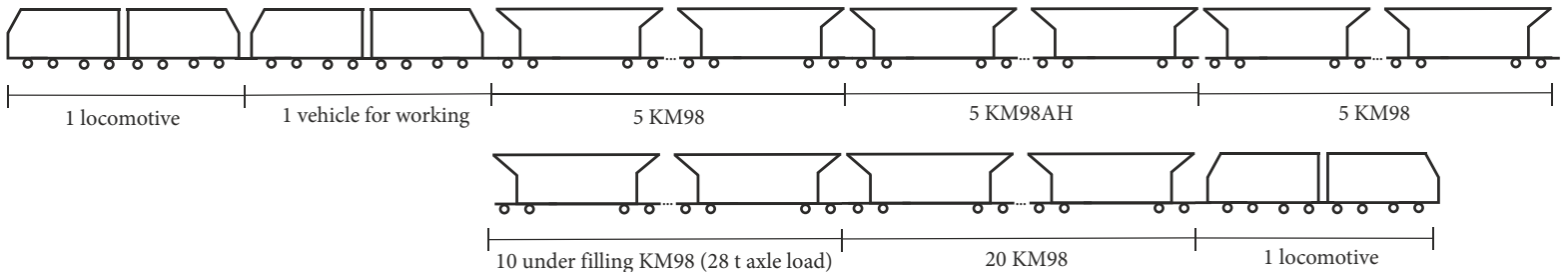

c)

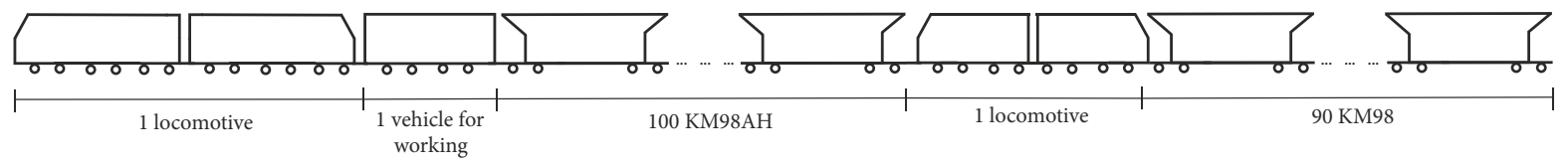

Figure 3. Formations of the test trains: a - characteristic lengths of KM98 vehicle; $b-5400 t$ test train; $c-23000 t$ test train

\subsection{Test methods}

A large amount of researches on the structural monitoring has been undertaken recently under the development of high-speed and heavy-haul rail lines (Zhai et al. 2014; Kouroussis et al. 2016). Kouroussis et al. (2015), focusing on stress-based solutions, reviewed conventional and non-conventional methods to monitor the train traffic and presented their advantages and limitations. Despite of the disadvantage of electromagnetic interference, owning to its low expense, conventional strain gauge sensors are still one of the most accurate approach to detect the dynamic load, which has been widely adopted by recent researches (Zhai et al. 2013, 2014; Zhang et al. 2016). In this paper, the test methods for wheel-rail dynamic forces employed in Chinese railway Standard TB/T 2489-1994 were adopted herein. Moreover, the test methods for deformations and vibrations of track structure proposed by Zhai (2015) were referenced.

\subsubsection{Wheel-rail dynamic force}

As shown in Figure 4, the multiple-element shear strain gauges were installed on the rail web and rail bottom to measure the wheel-rail vertical and lateral forces. To de- termine the vertical wheel-rail force, eight gauges were attached to the rail web at the positions near the neutral axis, $110 \mathrm{~mm}$ far from the mid-span of the sleepers, and keeping the strain gauge gridlines at $45^{\circ}$ relative to the rail axis. These strain gauges were then connected to form a full bridge circuit. Similarly, in order to collect the lateral wheel-rail force signals, other eight strain gauges were attached to the rail bottom $20 \mathrm{~mm}$ far from its edge, $110 \mathrm{~mm}$ far from the mid-span of the sleepers, keeping the strain gauge gridlines at $45^{\circ}$ relative to the rail axis. Then, a full bridge circuit was constructed.

\subsubsection{Deformations of track structure}

The displacement sensors used in the dynamic deformation test of the track structure were installed as shown in Figure 5. The measurement range is $-10 \ldots 10 \mathrm{~mm}$, and its sensitivity coefficient is $0.500 \mathrm{~V} / \mathrm{mm}$. Before testing, two steel columns were planted into the subgrade bed. Then, the displacement sensors were fixed on the steel columns using homemade fixtures. It should be noticed that ensuring the thimbles of the displacement sensors in contact with the insulating boards on the bottom surface of the rail, a side of the rail-head and the upper surface of the sleeper are required. 


\subsubsection{Vibration of track structure}

Vibration responses of rail, sleeper and ballast have been measured and are shown in Figure 6. The accelerometers for the rail vibration measurement were mounted on the top surface of the rail bottom, and those for sleeper vibration measurement on the top of the sleepers. The measurement range of the rail accelerometer is $(0 \ldots 1000) \cdot g$

$\left(g=9.8 \mathrm{~m} / \mathrm{s}^{2}\right)$, and that for the sleeper accelerometers is $(0 \ldots 50) \cdot g$. The effective frequency range of both the rail and the sleeper accelerometers is $0.5 \ldots 10000 \mathrm{~Hz}$.

It should be noted that the extrusions on the accelerometers and sensor cables induced by ballast particles should be avoided during the process of ballast bed vi-

a)

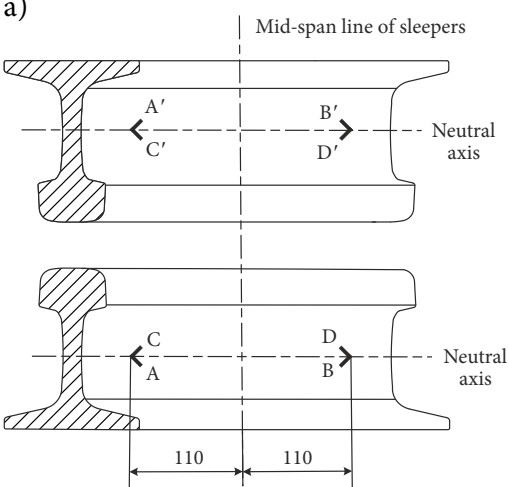

b)

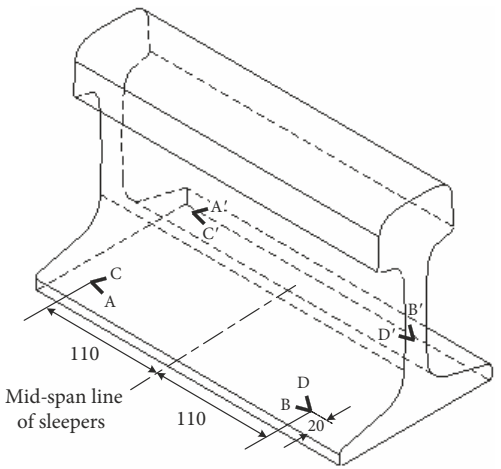

c)

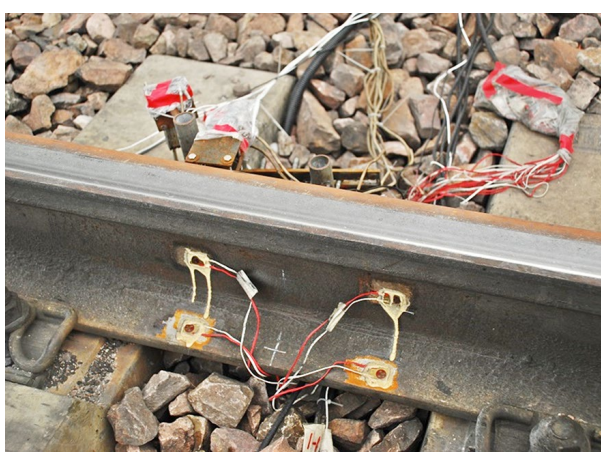

Figure 4. Wheel-rail dynamic force test scheme: a - strain gauge arrangement for vertical force measurement; $\mathrm{b}$ - strain gauge arrangement for lateral force measurement; $\mathrm{c}$ - photo of the field testing

a)

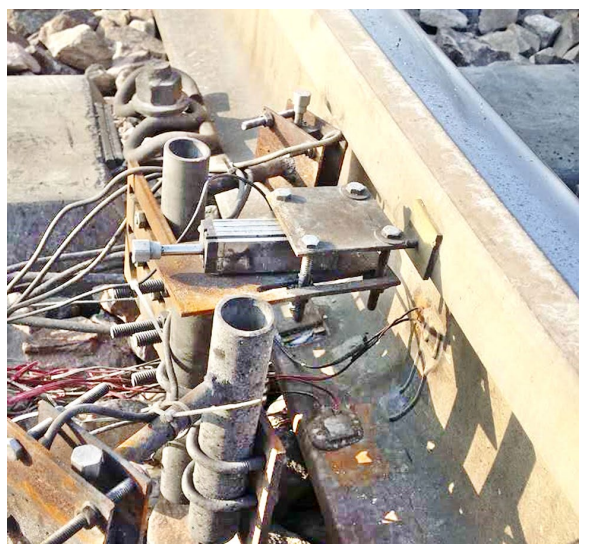

b)

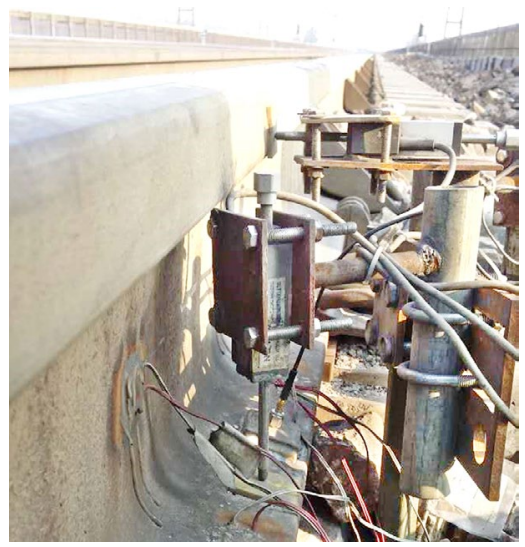

c)

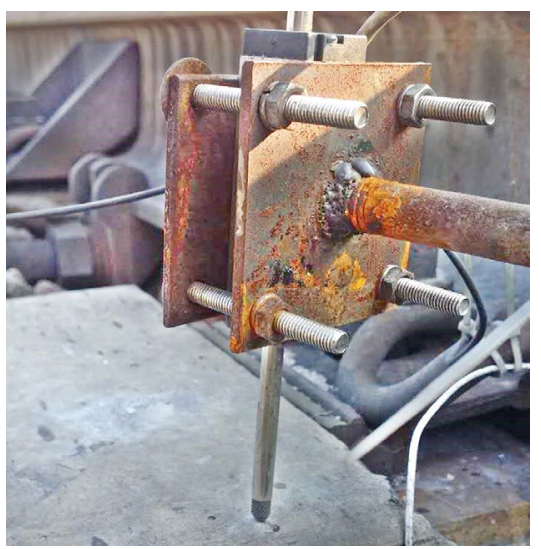

Figure 5. Arrangement of displacement sensors along: a - rail lateral direction; b - rail vertical direction; $\mathrm{c}$ - sleeper vertical direction

a)

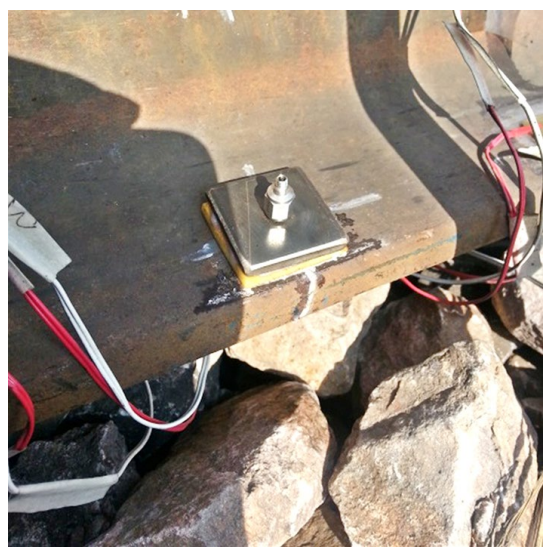

b)

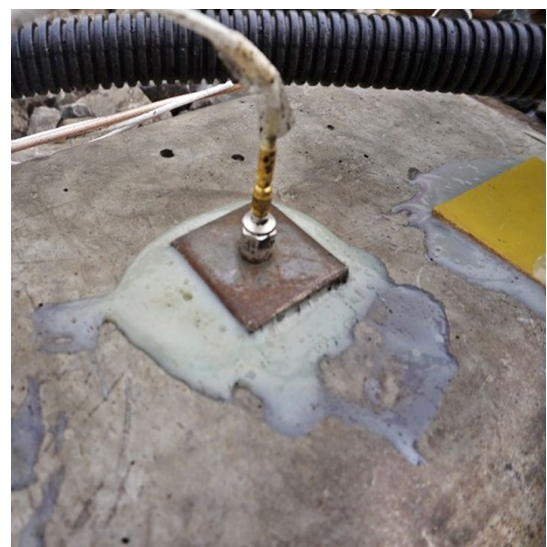

c)

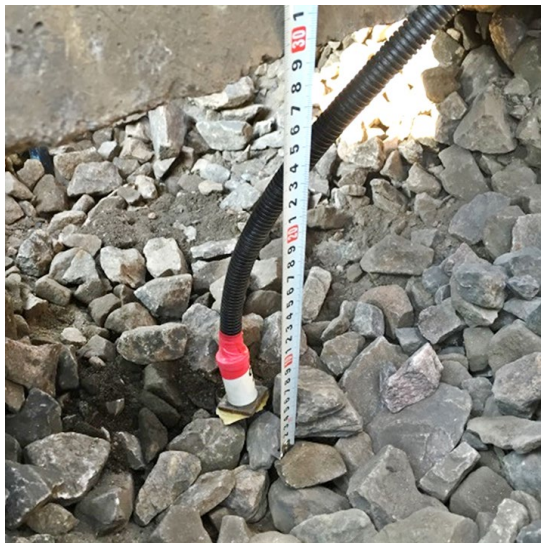

Figure 6. Arrangement of accelerometers for vertical vibration test: a - rail; b - sleeper; c - ballast at $300 \mathrm{~mm}$ depth 
bration measurement. Consequently, the accelerometers were fixed to the PVC pipe with a special protective box, and the sensor cables buried in ballast bed were wrapped with rubber hoses. The bottom of the protective box was designed as a square sheet to facilitate the positioning of the box, so as to keep the accelerometer in the vertical direction. In order to reduce the effect of the box on the measured acceleration signals as much as possible, the dimensions of the protective box were designed to be similar to the ballast particles, and it is expected not to change the ballast bed structure. Before testing, the ballast particles under the sleepers at the test section were clawed, and then the sensors were placed vertically under the sleepers at a depth of $300 \mathrm{~mm}$.

\subsection{Data acquisition}

A portable data acquisition system was employed to collect the signals. The data acquisition plan was programmed in imc DEVICES (https://www.imc-tm.de) with the sampling frequency of $1000 \mathrm{~Hz}$ for the dynamic force and displacement testing, and with $10000 \mathrm{~Hz}$ for the acceleration testing. This sampling frequency ensures that the high-frequency dynamic impacts and the corresponding structural responses can be captured during the test.

\section{Results and discussions}

\subsection{Analysis on the measured time histories results}

The wheel-rail dynamic force was calculated by the recorded microstrain signal and a calibration coefficient. The displacement and the acceleration signals were obtained by multiplying the corresponding recorded voltage values with the calibration coefficients, which were determined by the sensitivity of the sensor and the gain of the amplifier and the recorder.

Figure 7 shows an example of the time history of the collected microstrain signal from the shear gauge bridge on the vertical force of the outer rail when the $5400 \mathrm{t}$ test train runs at the speed of $60 \mathrm{~km} / \mathrm{h}$. The initial reading and the significant microstrain peak value generated by each passing wheel are clearly observed. As is shown, the average values of the peaks for vehicle show higher amplitude compared with those for locomotive. Moreover, since distances between bogie centres for a locomotive and a vehicle are different, the recorded results on the time histories exhibit different shape.

The time histories of the measured wheel-rail dynamic forces and vibrations are shown in Figures 8 and 9, respectively. Here the $5400 \mathrm{t}$ formation train runs at the speed of $75 \mathrm{~km} / \mathrm{h}$. It can be seen in Figure 8 that the wheel-rail

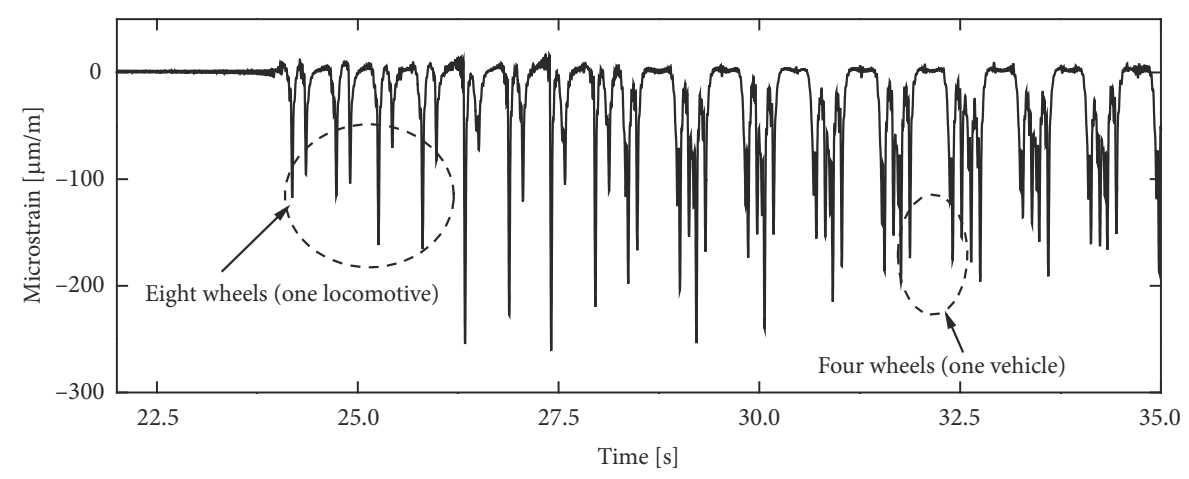

Figure 7. Microstrain signal representing the wheel-rail vertical dynamic forces

a)

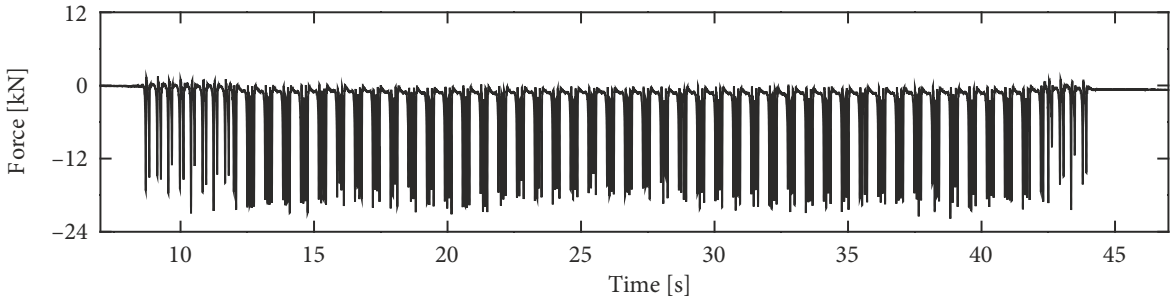

b)

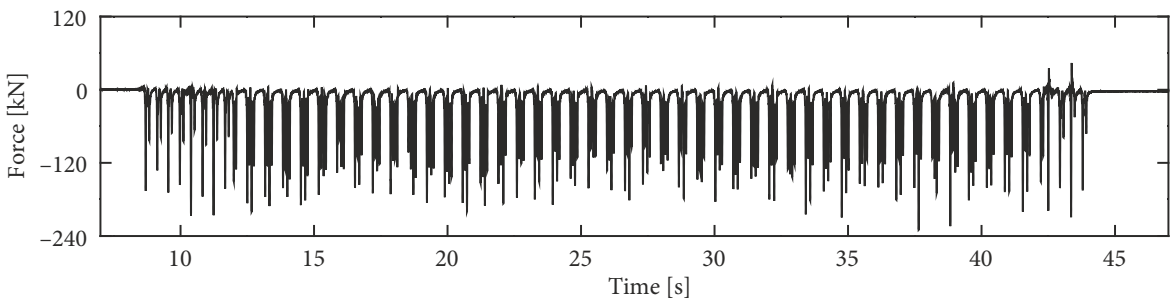

Figure 8. Time histories of wheel-rail dynamic force: $\mathrm{a}$ - lateral; b - vertical 
lateral and vertical forces of the locomotives can be clearly distinguished from that of the wagon vehicles by the signal amplitude and shape. The peak value of the wheel-rail lateral force lies in the range of $16.2 \ldots 21.8 \mathrm{kN}$, and that of wheel-rail vertical force is in $148 \ldots .227 \mathrm{kN}$.

Similarly, the time histories of the rail lateral displacement, rail vertical displacement, sleeper vertical displacement, rail vertical acceleration, sleeper vertical acceleration and ballast vertical acceleration are collected, which are shown in Figure 9. It can be seen that the peak value of the rail lateral displacement is in the range of $0.45 \ldots 0.61 \mathrm{~mm}$, and that of the rail and the sleeper vertical displacements are $1.97 \ldots 2.10$ and $0.97 \ldots 1.07 \mathrm{~mm}$. The measured peak values of the-vertical acceleration for the rail, the sleeper vertical acceleration and the ballast vertical acceleration were found to be in the range of $(6.77 \ldots 11.96) \cdot g,(0.54 \ldots 1.22) \cdot g$ and $(90.32 \ldots 0.81) \cdot g$, respectively. Based on the measured data, the vibration transfer ratio of rail, sleeper and ballast bed can be calculated, which is 12.49:1.52:1.

a)

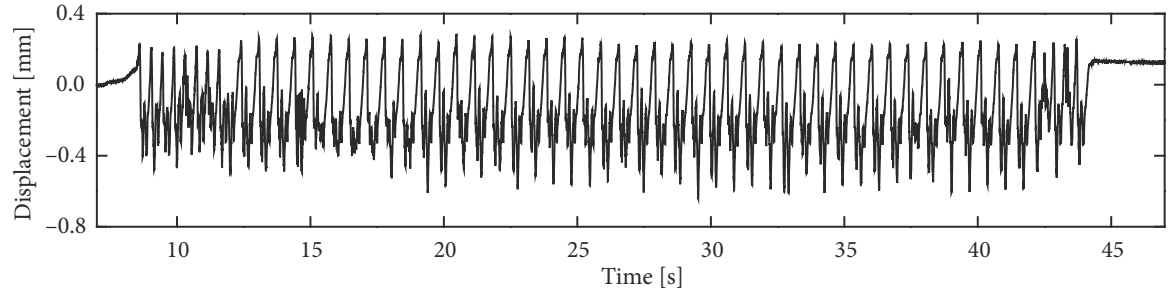

b)

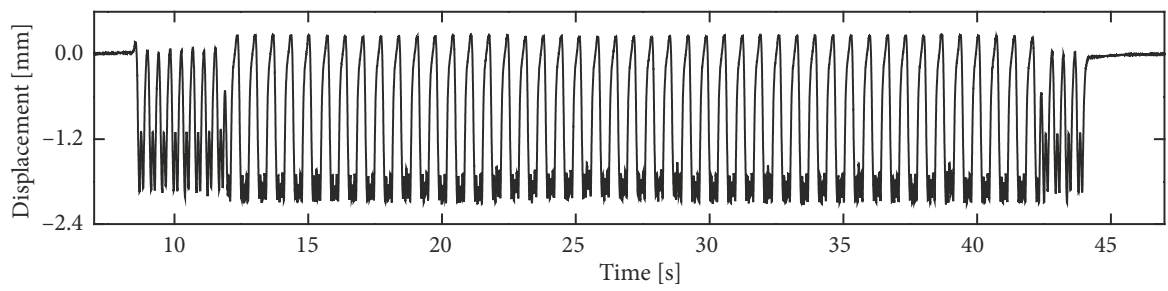

c)

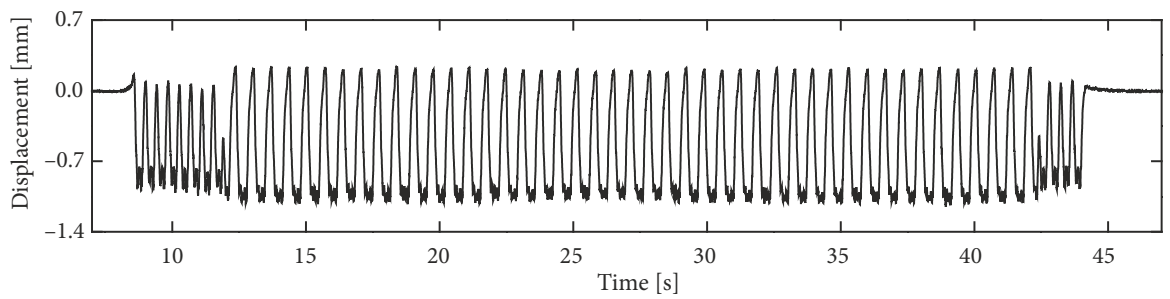

d)

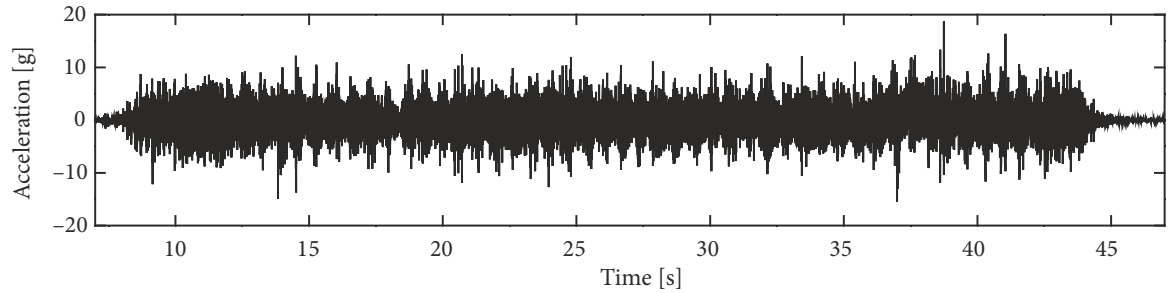

e)

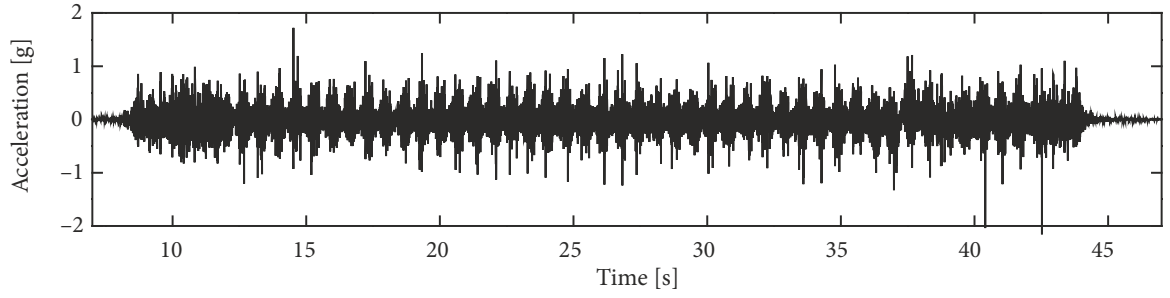

f)

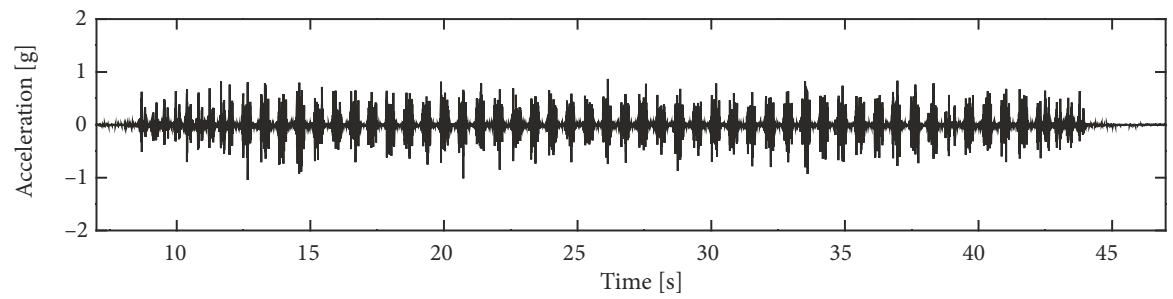

Figure 9. Time histories of the track vibration: $\mathrm{a}$ - rail lateral displacement; $\mathrm{b}$ - rail vertical displacement; $\mathrm{c}$ - sleeper vertical displacement; $\mathrm{d}$ - rail vertical acceleration; $\mathrm{e}$ - sleeper vertical acceleration; $\mathrm{f}$ - ballast vertical acceleration 


\subsection{Variations of the statistical indicators}

The peak values of the collected time histories were extracted and analysed. Prior to extraction of the peak signals, the recorded data were filtered using the filters whose algorithm was selected on the base of the concerned frequency components and the data characteristics. An $80 \mathrm{~Hz}$ low-pass filter on the wheel-rail lateral/vertical force and a band-stop filter between 49.9 and $50.1 \mathrm{~Hz}$ for elimination of the Chinese AC power frequency $(50 \mathrm{~Hz})$ induced interference were adopted in this study. Since experiments under the same conditions were conducted for several times, the averaged experimental data were used in the analysis of this paper. Then, a linear fitting algorithm was employed to obtain the variations of the statistical indicators with the influencing factors. The fitting function is depicted as:

$$
y=\beta_{0}+\beta_{1} \cdot x
$$

where: $\beta_{0}$ is the intercept; $\beta_{1}$ is the slope (it should be noted that the fitting function is only used for describing the variation trend of the results in this test, not for the future prediction).

\subsubsection{Comparison of all indicators between two different conditions}

To investigate the influence of the heavier axle load on the dynamic response of the railway track, a comparison of all the indicators on both rail sides between $25 \mathrm{t}$ axle load condition and $30 \mathrm{t}$ axle load condition can be listed in Table 2. It is shown that compared with the $25 \mathrm{t}$ axle load condition, the peak values of the wheel-rail lateral/vertical force, rail lateral displacement, sleeper/ballast and bed vertical acceleration under $30 \mathrm{t}$ axle load show $17,10,10$, 7 and 30\% growth for outer rail side and 14, 7, 5, 18 and $30 \%$ growth for inner rail side, respectively. However, the peak values of rail vertical displacement and acceleration show a little growth, namely $0,2 \%$ for outer rail side and $4,2 \%$ for inner rail side, respectively. It can be concluded that the increasing axle load influences vibrations and wheel-rail forces more than the deformations.

Moreover, a growth trend can be observed for the percentage of indicators on both sides, which implies that the axle load effect is more relevant on the bottom of the structure. The outer and the inner rail side do not show obviously different increase. It can be concluded that the axle load affect the outer and the inner rail sides similarly.

\subsubsection{Effect of the train speed}

With the increase of the train speed, the statistical indicator, namely the peak value of the measured signals, exhibits different changing tendencies. Figures 10 and 11 depict the variations of the peak value for all the measured indicators on outer rail side with the train speed varying from 10 to $75 \mathrm{~km} / \mathrm{h}$. The axle loads of the vehicles are $30 \mathrm{t}$. In these figures, the horizontal axis indicates the train speed selected for testing and the vertical axis represents the averaged peak values of the corresponding indicators. Furthermore, the peak values of these indicators appear to be linear with the train speed.

The statistical relationships between the wheel-rail lateral and vertical forces and the train running speed are illustrated in Figure 10 where all the operation conditions are kept unchanged except the running speed. It can be seen that the lateral force increases linearly with the train running speed. The quantified relationship can be obtained by fitting linearly the wheel-rail lateral force and the train running speed, and the obtained equation is shown in this figure. While for the wheel-rail vertical force, it varies from 181.4 to $187.2 \mathrm{kN}$ with the increase of the train running speed. However, the slope of the fitted line for the wheel-rail vertical force shown in Figure $10 \mathrm{~b}$ is much more gently than that for the lateral force in Figure 10a. This implies that the wheel-rail vertical force is not much sensitive to the train running speed as the wheel-rail lateral force.

The effect of the speed on the impact force from different impacts has been studied analytically and experimentally by researchers: Wu and Thompson (2002), Esveld (2001), Auersch (2010). Wu and Thompson (2002) analytically studied the wheel flats impact and found that for different types of wheel flat, the effect of train speed on the impact force is different. Esveld (2001) studied the bad welds and found similar signal shapes to those from wheel flats. It is worthy to be noted that even if the dynamic amplification of the impact forces from bad welds substan-

Table 2. A comparison of all indicators between different conditions

\begin{tabular}{|c|c|c|c|c|c|c|c|c|c|}
\hline \multirow{2}{*}{ Indicator } & \multirow{2}{*}{ Unit } & \multicolumn{2}{|c|}{$25 \mathrm{t}$ axle load } & \multicolumn{2}{|c|}{$30 \mathrm{t}$ axle load } & \multicolumn{2}{|c|}{ Difference } & \multicolumn{2}{|c|}{ Percentage [\%] } \\
\hline & & outer & inner & outer & inner & outer & inner & outer & inner \\
\hline Wheel-rail lateral force & $\mathrm{kN}$ & 14.9 & 14.3 & 17.37 & 16.74 & 2.47 & 2.01 & 17 & 14 \\
\hline Wheel-rail vertical force & $\mathrm{kN}$ & 169.44 & 165.86 & 185.64 & 177.46 & 16.20 & 11.6 & 10 & 7 \\
\hline Rail lateral displacement & $\mathrm{mm}$ & 0.666 & 0.375 & 0.734 & 0.395 & 0.07 & 0.02 & 10 & 5 \\
\hline Rail vertical displacement & $\mathrm{mm}$ & 1.921 & 3.180 & 1.921 & 3.305 & 0 & 0.125 & 0 & 4 \\
\hline Sleeper vertical displacement & $\mathrm{mm}$ & 0.934 & 2.941 & 0.992 & 3.098 & 0.06 & 0.157 & 6 & 5 \\
\hline Rail vertical acceleration & g & 9.20 & 6.31 & 9.36 & 6.41 & 0.16 & 0.1 & 2 & 2 \\
\hline Sleeper vertical acceleration & g & 0.84 & 0.84 & 0.90 & 0.99 & 0.06 & 0.15 & 7 & 18 \\
\hline Ballast bed vertical acceleration & $\mathrm{g}$ & 0.50 & 0.54 & 0.65 & 0.65 & 0.15 & 0.11 & 30 & 20 \\
\hline
\end{tabular}


tially increases with the increments of the train speeds in a large range, and a decreasing trend can be found in the speed range of $45 \ldots 75 \mathrm{~km} / \mathrm{h}$. In this test, the train speed in the range of $40 \ldots 75 \mathrm{~km} / \mathrm{h}$ is taken into consideration and it can be seen that the magnitude of the wheel-rail vertical force is independent on the train speed.

The statistical indicators extracted from the measured variation of the peak value of the rail lateral displacement with train running speed is shown in Figure 11a. As the train speed increases, the peak value of lateral displacement varies in a small range, namely $0.71 \ldots 0.77 \mathrm{~mm}$. In addition, the variation tendency is non-monotonic as the growth of the train running speed. Figure $11 \mathrm{~b}$ shows the peak value variation of the measured rail vertical displacement with respect to train running speed. It varies from 1.82 to $2.09 \mathrm{~mm}$ with the similar tendency as the wheel-rail lateral force that is shown in Figure 11a. Meanwhile, the sleeper vertical displacement was also measured in the field test. Figure 11c illustrates its variation in $0.98 \ldots 1.04 \mathrm{~mm}$ with the train speed increasing. Furthermore, it can be also observed that the changing tendency of the sleeper vertical displacement is in accordance with the rail vertical displacement shown in Figure 11b. It should be noted that the ratio of the peak value of the rail vertical displacement to that of the sleeper is 1.92 . A conclusion can be derived from Figures $11 \mathrm{a}-\mathrm{c}$, that the train running speed has just a little effect on the rail lateral/vertical displacement and on the sleeper vertical displacement.

It is worthy pointing out that in Figures $10 \mathrm{a}$ and $11 \mathrm{a}$, the wheel/rail lateral force exhibits a different trend compared with the rail lateral displacement with the increasing train speed. This may be due to the fact that the peak values of the rail lateral force are in a weak peak range (no more than $22 \mathrm{kN}$ ).

Variations of the vertical acceleration peak values of the rail, the sleeper and the ballast bed as the increase of the train running speed are displayed in Figures 11d-f. As shown in Figure 11d, peak values of the rail vertical acceleration present an increase trend in the whole speed range for the test from 10 to $75 \mathrm{~km} / \mathrm{h}$. The peak value reaches its maximum $(9.77 \cdot g)$ at the speed of $75 \mathrm{~km} / \mathrm{h}$. Figure 11e illustrates how the sleeper vertical acceleration changes as train speed increases, and similarly an approximate linear relationship can be found. It reaches the maxi-

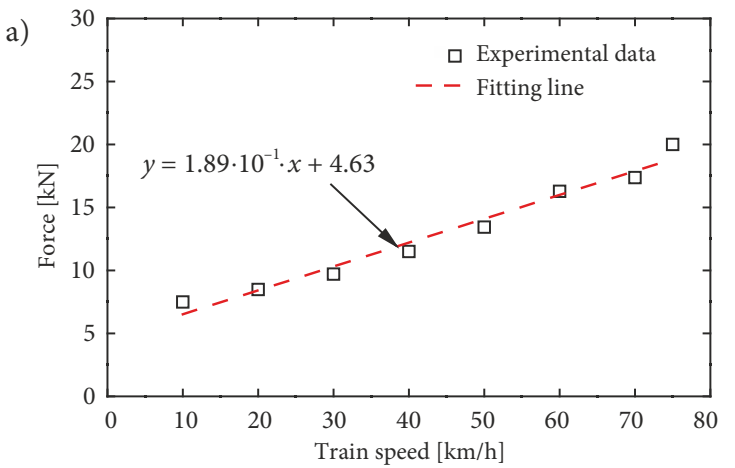

mum $(1.18 \cdot g)$ at the speed of $75 \mathrm{~km} / \mathrm{h}$. Figure $11 \mathrm{f}$ shows the variation of the peak value of the ballast bed vertical acceleration with the increase of the train running speed. It can be found that as the train speed increases, the peak value increases linearly to the maximum value $(0.61 \cdot g)$.

\subsubsection{Effect of the axle load}

Variations of the peak value for all the measured indicators with axle load varying from 21 to $30 \mathrm{t}$ are shown in Figures 12 and 13 . The train speed is $70 \mathrm{~km} / \mathrm{h}$. In these figures, the horizontal axis indicates the axle load, which varies from 21 to $30 \mathrm{t}$, and the vertical axis represents the averaged peak values of the corresponding indicators.

Statistical relationships between the wheel-rail lateral force and the axle load are shown in Figure 12a where all the operation conditions are kept unchanged except the axle load. It can be seen that the lateral force changes irregularly as the axle load increases. Comparing with Figure 10a, it can be inferred that the lateral force is impacted by the train speed more than the axle load.

Figure $12 \mathrm{~b}$ illustrates the variation between the wheelvertical force and the axle load. The wheel-rail vertical forces under 21, 23, 25, 28 and $30 \mathrm{t}$ axle load are 151.72, $158.99,169.44,177.98$ and $185.64 \mathrm{kN}$, respectively. A linear growth of the wheel-rail vertical force is observed in Figure 12b as axle load increases. It can be seen that the axle load is one of the most important factors influencing wheel-rail vertical force.

Figures $13 a-c$ illustrates the variation of the peak value of the rail lateral displacement, the rail vertical displacement and the sleeper vertical displacement. As the axle load increases, the peak value of rail lateral displacement varies from 0.71 to $0.77 \mathrm{~mm}$. Compared with Figure 11a, it can be concluded, that neither the axle load nor the train speed influences the rail lateral displacement significantly in the train speed range of $10 \ldots 75 \mathrm{~km} / \mathrm{h}$ and the axle load range of $21 \ldots 30 \mathrm{t}$. Figure $13 \mathrm{~b}$ shows the peak value variation of the measured rail vertical displacement versus the axle load. It can be found that peak values of the rail vertical displacement under 21,23, 25, 28 and $30 \mathrm{t}$ axle load are $1.872,1.885,1.921,1.962$ and $1.921 \mathrm{~mm}$, and this variation tendency is in accordance with the wheel-rail vertical dynamic force. Figure 13c illustrates an increasing trend of the peak value from 0.87 to $0.99 \mathrm{~mm}$ as the axle

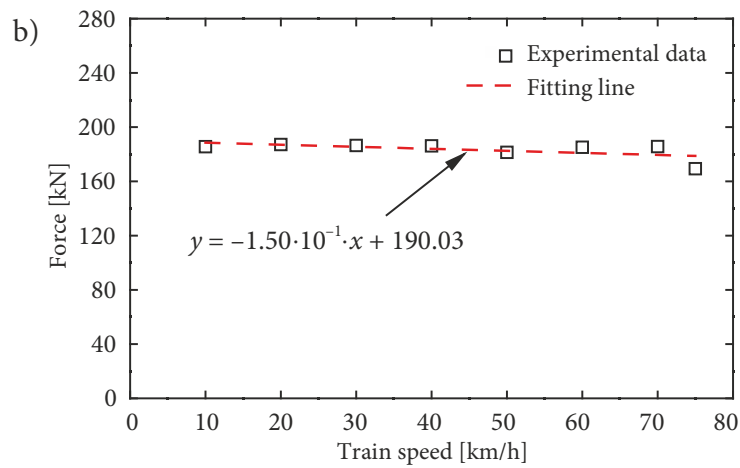

Figure 10. Variations of the peak values of the wheel-rail force with train running speed: $a$ - lateral; b - vertical 
load increases. Meanwhile, it can also be observed that the trend is in accordance with that in the rail displacement shown in Figure 13b. It should be noted, that the ratio of the peak value of the rail vertical displacement
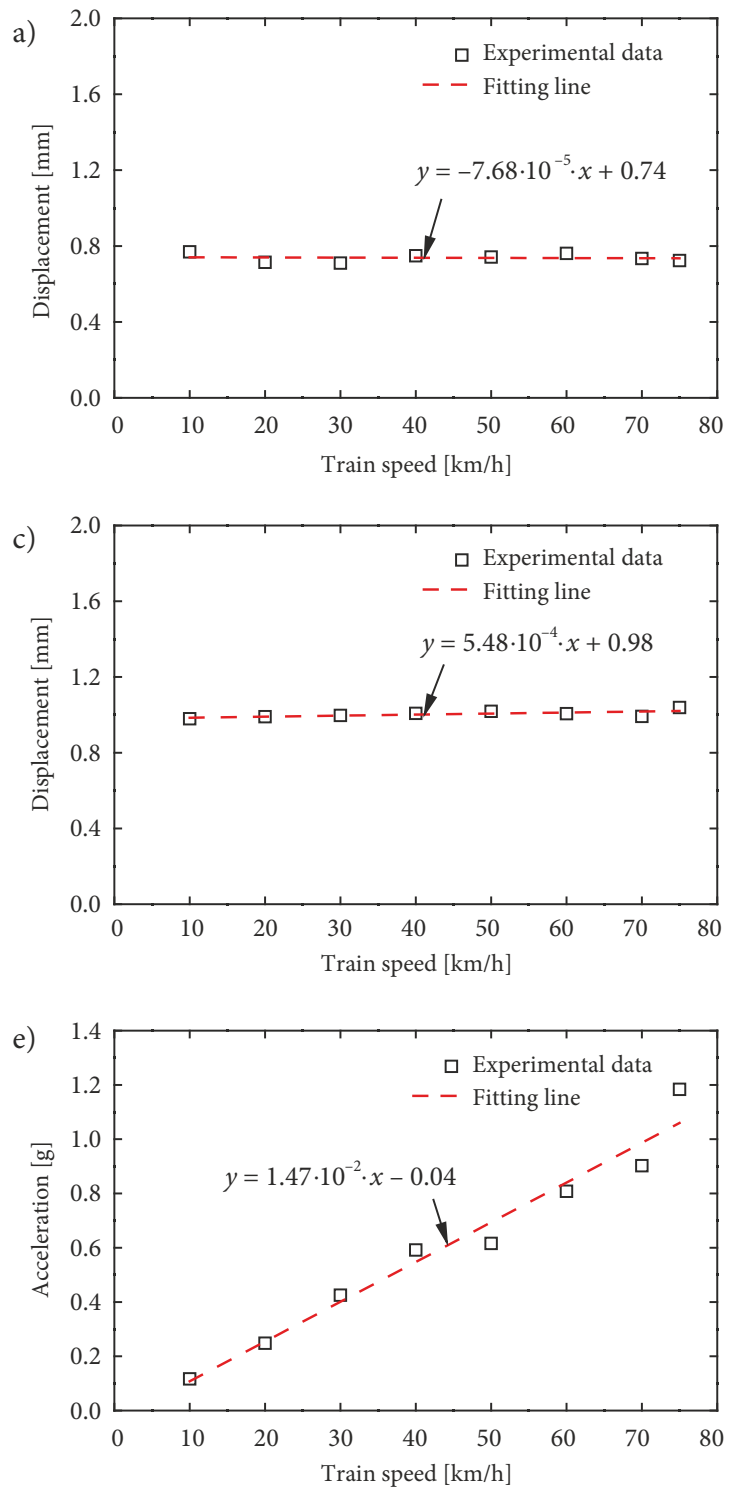

to that of the sleeper is 2.05. A conclusion can be derived from Figures 13a-c that effect on the rail lateral/vertical displacement and on the sleeper vertical displacement are not significant.
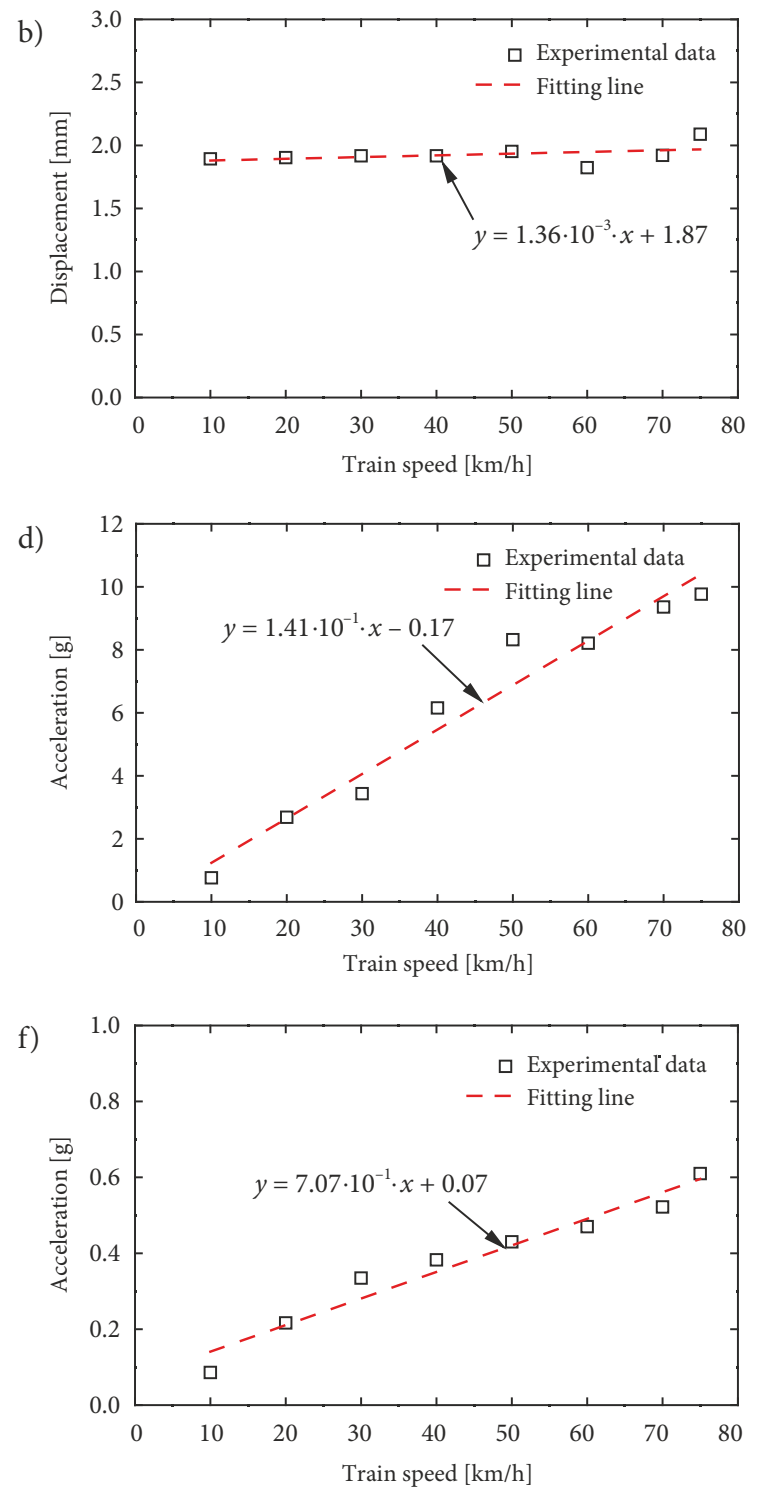

Figure 11. Statistical results as increase of train running speed: $\mathrm{a}$ - rail lateral displacement; $\mathrm{b}$ - rail vertical displacement; c - sleeper vertical displacement; $d$ - rail vertical acceleration; $\mathrm{e}$ - sleeper vertical acceleration;

$\mathrm{f}$ - ballast bed vertical acceleration vary with train speed increasing
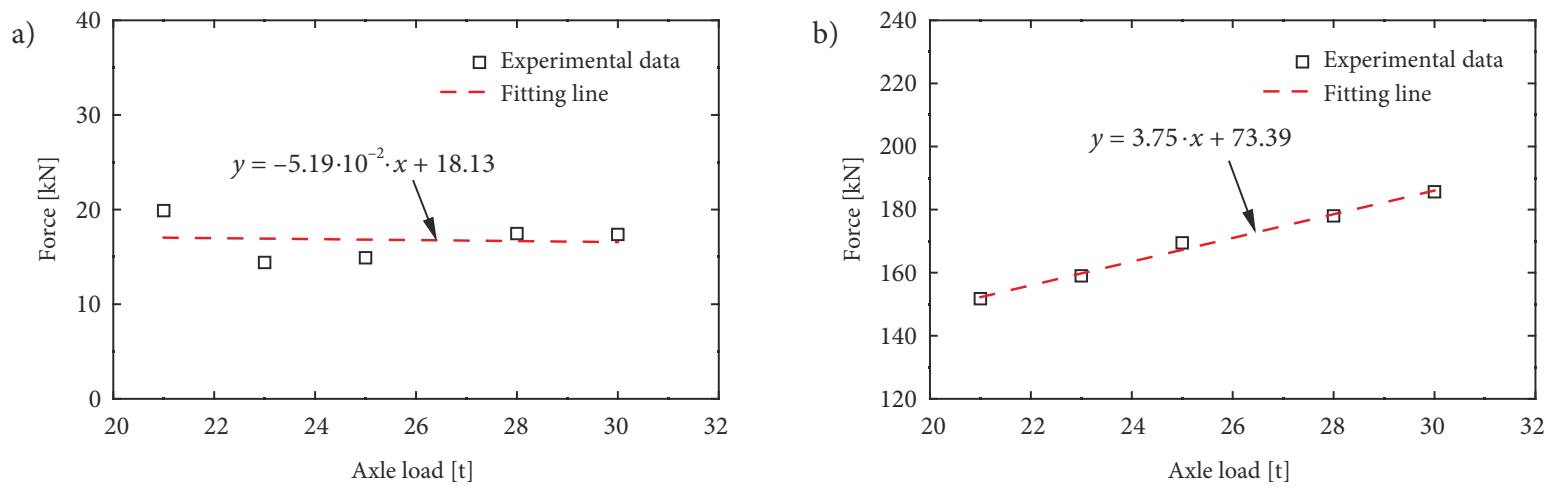

Figure 12. Variations of the peak values of the wheel-rail force with axle load: $\mathrm{a}$ - lateral; $\mathrm{b}$ - vertical 

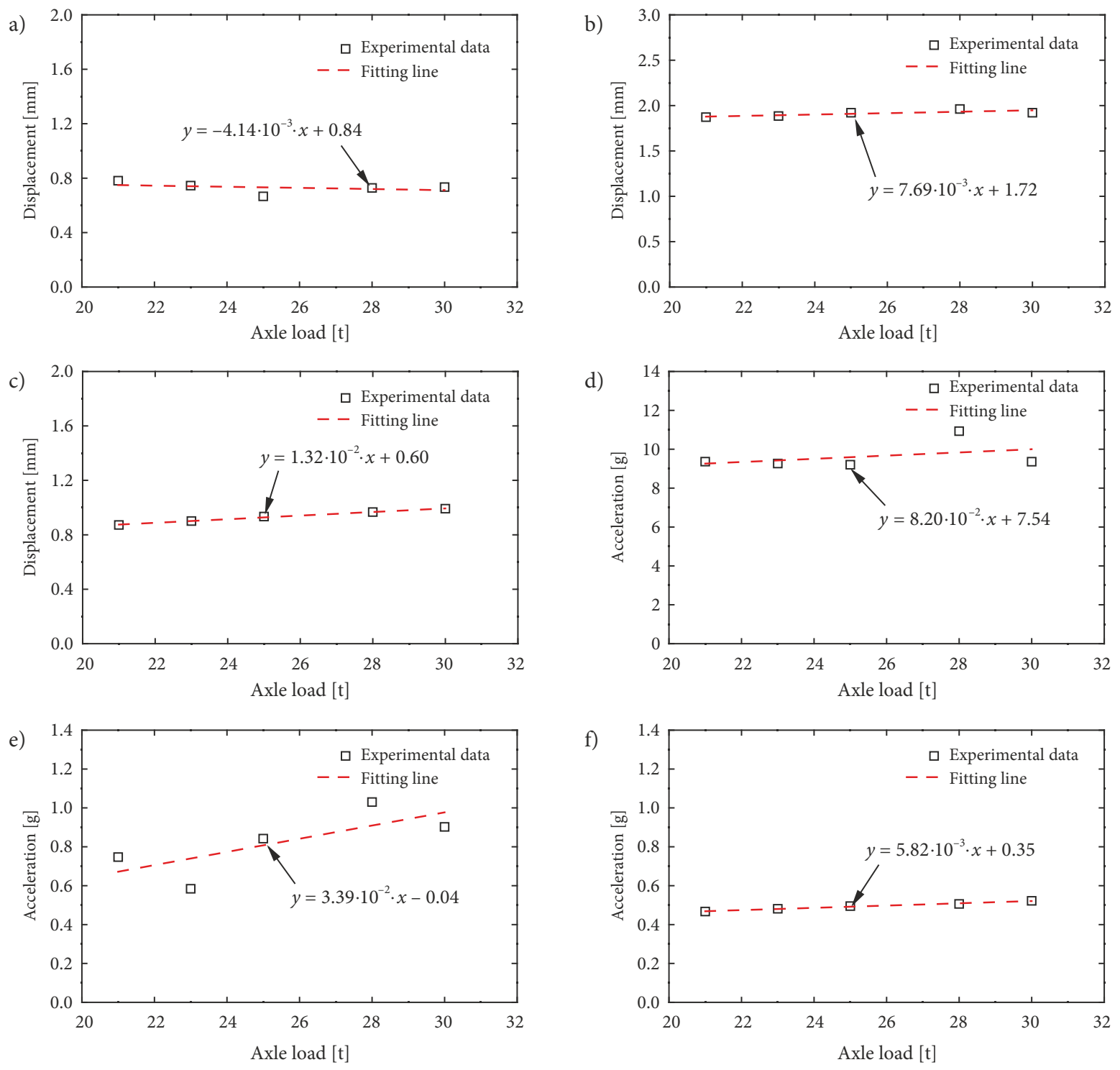

Figure 13. Statistical results as increase of train running speed: a - rail lateral displacement; b - rail vertical displacement; $\mathrm{c}$ - sleeper vertical displacement; $\mathrm{d}$ - rail vertical acceleration; e - sleeper vertical acceleration; $\mathrm{f}$ - ballast bed vertical acceleration variation with increasing axle load

Variations of the vertical acceleration peak values of the rail, the sleeper and the ballast bed as the increase of the axle load are shown in Figures 13d-f. As axle load increases from 21 to $30 \mathrm{t}$, peak values of the rail vertical acceleration vary from $9.20 \cdot \mathrm{g}$ to $10.93 \cdot \mathrm{g}$. A slow growing trend can be observed from Figure 13d. Comparing with the peak value of the rail vertical acceleration under $21 \mathrm{t}$ axle load, the peak value under $30 \mathrm{t}$ shows $15 \%$ growth. Figure 13e illustrates the changing tendency of the sleeper vertical acceleration, and it reaches the maximum under the axle load of $28 \mathrm{t}$. The peak values under $21,23,25,28$ and $30 \mathrm{t}$ are $0.75 \cdot g, 0.585 \cdot g, 0.845 \cdot g, 1.03 \cdot g$ and $0.90 \cdot g$, respectively. As a result, in comparison with the peak value of the sleeper vertical acceleration under $21 \mathrm{t}$ axle load, the peak value under $30 \mathrm{t}$ axle load increases by $12 \%$. Peak values of the ballast vertical acceleration are shown in Figure 13f. It can be found that with an increasing axle load, the peak value of the ballast bed vertical acceleration exhibits a slow growing trend. Compared with the peak value of the ballast bed vertical acceleration under $21 \mathrm{t}$ axle load, the peak value under $30 \mathrm{t}$ axle load shows a $10 \%$ growth.

\section{Conclusions}

A field experimental test on the dynamic behaviour of a heavy-haul railway track structure was performed on Shuo-Huang railway in China. During the test, the trains ran on the ballast track with several running speed levels from 10 to $75 \mathrm{~km} / \mathrm{h}$, and the axle load level varies from 21 to $30 \mathrm{t}$. The time history results record the amplitudes of all indicators, the shapes of signals induced by different types of vehicles, and other implicit information. The tested results for 25 and $30 \mathrm{t}$ axle load conditions are compared, so that increments of different indicators can be 
revealed and expected to be used for practical guidance. Besides, the discussion on the effects of the train speed and the axle load may inspire new thinking on predicting dynamic behaviour of the railway track structure as the train speed and the axle load continue to increase. Some conclusions can be drawn from this study as follows:

1. conventional testing methods can effectively measure the dynamic behaviour of railway track structure, and the corresponding time history results are presented. Under the $30 \mathrm{t}$ axle load and $75 \mathrm{~km} / \mathrm{h}$ train speed conditions of this test, the peak values of the wheel-rail lateral force, the wheel-rail vertical force, the rail lateral displacement, the rail vertical displacement, the sleeper vertical displacement, the rail vertical acceleration, the sleeper vertical acceleration and ballast vertical acceleration lie in the range of $16.2 \ldots 21.8,148 \ldots 227 \mathrm{kN} ; 0.45 \ldots 0.61,1.97 \ldots 2.10$, $0.97 \ldots 1.07 \mathrm{~mm} ;(6.77 \ldots 11.96) \cdot g,(0.54 \ldots 1.22) \cdot g$ and $(0.32 \ldots 0.81) \cdot g$, respectively;

2. the axle load affects the vibrations and the wheelrail force more than deformations. The vibration increases in the propagation from the rail to the ballast bed. A similar effect can be found on both the inner and the outer rail sides;

3. the results of this test demonstrate that the wheelrail lateral force is affected by the train speed significantly, and the wheel-rail vertical force is influenced by the axle load considerably. Neither the train speed nor the axle load exhibit an obvious effect on the structure dynamic deformations in this shortterm test. Linear upward tendencies are exhibited with the increase of the train running speed and the axle load for the structure dynamic vibrations. However, the impact of the train speed is more obvious than that of the axle load on the dynamic vibration performance of the track structure.

It is worth pointing out that the long-term service performance of the railway track is likely to be affected by the axle load, which is necessary to be further studied in the future.

\section{Funding}

This work was supported by the National Natural Science Foundation of China under Grant No 51825504 and the Open Projects of State Key Laboratory for Track Technology of High-Speed Railway under Grant No 2016YJ001.

\section{Acknowledgments}

The authors would like to thank the State Key Laboratory of Traction Power for providing office, equipment, and materials to this project, and the Shuohuang Railway Development Co., Ltd. for the cooperation and support.

We thank Zhaowei Chen, Xu Zhang, Xuancheng Yuan, Zhaoling Han and Yang Feng for their assistance in the in-situ test and data processing, Martina Meacci for her help in language improvement.

\section{References}

Al Shaer, A.; Duhamel, D.; Sab, K.; Foret, G.; Schmitt, L. 2008. Experimental settlement and dynamic behavior of a portion of ballasted railway track under high speed trains, Journal of Sound and Vibration 316(1-5): 211-233.

https://doi.org/10.1016/j.jsv.2008.02.055

Askarinejad, H.; Dhanasekar, M.; Cole, C. 2013. Assessing the effects of track input on the response of insulated rail joints using field experiments, Proceedings of the Institution of Mechanical Engineers, Part F: Journal of Rail and Rapid Transit 227(2): 176-187. https://doi.org/10.1177/0954409712458496

Auersch, L. 2010. Theoretical and experimental excitation force spectra for railway-induced ground vibration: vehicle-tracksoil interaction, irregularities and soil measurements, Vehicle System Dynamics: International Journal of Vehicle Mechanics and Mobility 48(2): 235-261.

https://doi.org/10.1080/00423110802691515

Chupin, O.; Martin, A.; Piau, J.-M.; Hicher, P.-Y. 2014. Calculation of the dynamic response of a viscoelastic railway structure based on a quasi-stationary approach, International Journal of Solids and Structures 51(13): 2297-2307. https://doi.org/10.1016/j.ijsolstr.2014.02.035

Coelho, B.; Hölscher, P.; Priest, J.; Powrie, W.; Barends, F. 2011. An assessment of transition zone performance, Proceedings of the Institution of Mechanical Engineers, Part F: Journal of Rail and Rapid Transit 225(2): 129-139. https://doi.org/10.1177/09544097JRRT389

Colaço, A.; Costa, P. A.; Connolly, D. P. 2016. The influence of train properties on railway ground vibrations, Structure and Infrastructure Engineering: Maintenance, Management, LifeCycle Design and Performance 12(5): 517-534.

https://doi.org/10.1080/15732479.2015.1025291

Esveld, C. 2001. Modern Railway Track. MRT-Productions, 654 p.

Filippov, A. P. 1961. Ustanovivshiesya kolebaniya beskonechno dlinnoj balki, lezhashhej na uprugom poluprostranstve, pod dejstviem dvizhushhejsja sily, Izvestiya AN SSSR. Serija: Mehanika i mashinostroenie 6: 97-105. (in Russian).

Kouroussis, G.; Caucheteur, C.; Kinet, D.; Alexandrou, G.; Verlinden, O.; Moeyaert, V. 2015. Review of trackside monitoring solutions: from strain gages to optical fibre sensors, Sensors 15(8): 20115-20139. https://doi.org/10.3390/s150820115

Kouroussis, G.; Connolly, D. P.; Verlinden, O. 2014. Railwayinduced ground vibrations - a review of vehicle effects, International Journal of Rail Transportation 2(2): 69-110. https://doi.org/10.1080/23248378.2014.897791

Kouroussis, G.; Kinet, D.; Moeyaert, V.; Dupuy, J.; Caucheteur, C. 2016. Railway structure monitoring solutions using fibre Bragg grating sensors, International Journal of Rail Transportation 4(3): 135-150.

https://doi.org/10.1080/23248378.2016.1184598

Kouroussis, G.; Verlinden, O.; Conti, C. 2012. Influence of some vehicle and track parameters on the environmental vibrations induced by railway traffic, Vehicle System Dynamics: International Journal of Vehicle Mechanics and Mobility 50(4): 619639. https://doi.org/10.1080/00423114.2011.610897

Remennikov, A.; Kaewunruen, S. 2008. A review of loading conditions for railway track structures due to train and track vertical interaction, Structural Control and Health Monitoring 15(2): 207-234. https://doi.org/10.1002/stc.227

Remennikov, A.; Kaewunruen, S. 2006. Experimental investigation on dynamic railway sleeper/ballast interaction, Experimental Mechanics 46(1): 57-66.

https://doi.org/10.1007/s11340-006-5868-Z 
Sheng, X.; Jones, C. J. C.; Petyt, M. 1999. Ground vibration generated by a load moving along a railway track, Journal of Sound and Vibration 228(1): 129-156.

https://doi.org/10.1006/jsvi.1999.2406

TB/T 2489-1994. Track Side Test Methods of Vertical and Lateral Wheel-Rail Forces. Chinese Railway Standard (in Chinese).

Vostroukhov, A. V.; Metrikine, A. V. 2003. Periodically supported beam on a visco-elastic layer as a model for dynamic analysis of a high-speed railway track, International Journal of Solids and Structures 40(21): 5723-5752.

https://doi.org/10.1016/S0020-7683(03)00311-1

Wu, T. X.; Thompson, D. J. 2002. A hybrid model for the noise generation due to railway wheel flats, Journal of Sound and Vibration 251(1): 115-139.

https://doi.org/10.1006/jsvi.2001.3980

Young, T. H.; Li, C. Y. 2003. Vertical vibration analysis of vehicle/imperfect track systems, Vehicle System Dynamics: International Journal of Vehicle Mechanics and Mobility 40(5): 329-349. https://doi.org/10.1076/vesd.40.5.329.17912

Zeng, S. G. 1988. Dynamic tests for heavy haul railway tracks, Journal of the China Railway Society 10(2): 66-77. (in Chinese).

Zhai, W. M. 2015. Vehicle-Track Coupled Dynamics. Volume 1. 4th edition. Beijing: Science Press. 272 p. (in Chinese).

Zhai, W.; Gao, J.; Liu, P.; Wang, K. 2014. Reducing rail side wear on heavy-haul railway curves based on wheel-rail dynamic interaction, Vehicle System Dynamics: International Journal of Vehicle Mechanics and Mobility 52: 440-454. https://doi.org/10.1080/00423114.2014.906633

Zhai, W. M.; Wang, K. Y.; Lin, J. H. 2004. Modelling and experiment of railway ballast vibrations, Journal of Sound and Vibration 270(4-5): 673-683. https://doi.org/10.1016/S0022-460X(03)00186-X

Zhai, W.; Wang, S.; Zhang, N.; Gao, M.; Xia, H.; Cai, C.; Zhao, C. 2013. High-speed train-track-bridge dynamic interactions Part II: experimental validation and engineering application, International Journal of Rail Transportation 1(1-2): 25-41. https://doi.org/10.1080/23248378.2013.791497

Zhang, Z.; Wei, S.; Andrawes, B.; Kuchma, D. A.; Edwards, J. R. 2016. Numerical and experimental study on dynamic behaviour of concrete sleeper track caused by wheel flat, International Journal of Rail Transportation 4(1): 1-19. https://doi.org/10.1080/23248378.2015.1123657 